\title{
Ccl2/Cx3cr1-Deficient Mice: An Animal Model for Age-Related Macular Degeneration
}

\author{
Chi-Chao Chan ${ }^{\mathrm{a}}$ Robert J. Ross ${ }^{\mathrm{a}}$ Defen Shen $^{\mathrm{a}}$ Xiaoyan Ding ${ }^{\mathrm{a}}$ \\ Zigurts Majumdar $^{\mathrm{b}}$ Christine M. Bojanowski ${ }^{\mathrm{a}}$ Min Zhou ${ }^{\mathrm{a}} \quad$ Norman Salem, Jr. ${ }^{\mathrm{C}}$ \\ Robert Bonner $^{b}$ Jingsheng Tuo ${ }^{a}$ \\ a Section of Immunopathology, Laboratory of Immunology, National Eye Institute, bection on Medical Biophysics, \\ Laboratory of Integrative and Medical Biophysics, National Institute of Child Health and Human Development, \\ and ' Laboratory of Membrane Biochemistry and Biophysics, National Institute of Alcohol Abuse and Alcoholism, \\ National Institutes of Health, Bethesda, Md., USA
}

\section{Key Words}

Age-related macular degeneration - Animal model •

CCL2 - CX3CR1 - Retinal pigment epithelium •

$\mathrm{N}$-retinylidene- $\mathrm{N}$-retinylethanolamine $\cdot$ Chaperone $\cdot$

Omega-3 long-chain polyunsaturated fatty acids

\begin{abstract}
Background/Aims: Senescent $\mathrm{CCl} / 2^{-/-}$mice develop cardinal features of human age-related macular degeneration (AMD). Loss-of-function single-nucleotide polymorphisms within CX3CR1 are associated with AMD. Methods: We generated $\mathrm{CCl} 2^{-1-} / \mathrm{C} \times 3 \mathrm{Cr}^{-1-}$ [double-knockout (DKO)] mice and evaluated the eyes using fundoscopy routine histology, immunochemistry, biochemistry and proteomics. Results: At 6 weeks old, all DKO mice developed AMD-like retinal lesions such as abnormal retinal pigment epithelium cells, drusen, photoreceptor atrophy and choroidal neovascularization, which progressed with age and reversed with high omega-3 long-chain polyunsaturated fatty acid diet. N-retinylidene$\mathrm{N}$-retinylethanolamine (A2E), a major lipofuscin fluorophore, illustrated by an emission peak at $\sim 600 \mathrm{~nm}$, was significantly higher in DKO retinal pigment epithelium. Decreased
\end{abstract}

\section{KARGER}

Fax +4161306 1234

E-Mail karger@karger.ch

www.karger.com (c) 2008 S. Karger AG, Basel

0030-3747/08/0404-0124\$24.50/0

Accessible online at:

www.karger.com/ore
ERp29 was found in the retina of DKO mice. Conclusion: A broad spectrum of AMD pathologies with early onset and high penetrance in these mice implicate certain chemokines, A2E and endoplasmic reticulum proteins in AMD pathogenesis.

Copyright $\odot 2008$ S. Karger AG, Basel

\section{Introduction}

Age-related macular degeneration (AMD) typically affects people over the age of 50 and involves central visual field loss. Globally, AMD ranks as the third leading cause of visual impairment with a blindness prevalence of $8.7 \%$. In the elderly, however, AMD is the leading cause of worldwide blindness [1]. Conservatively, the World Health Organization estimated that 14 million persons, most of them in developed countries, are blind or are severely visually impaired due to this disease (http://www. who.int/blindness/causes/priority/en/print.html). Roughly $35-40 \%$ of the human population $>75$ years of age has some degree of AMD [2]. The exact pathogenesis of AMD remains unknown. Furthermore, to date, there 
is no known cure for this disease and the treatment options are limited [3]. Therefore, it is critical to study this disease using suitable animal models [4] including genetically engineered animal models. Although mice have no macula, the use of mouse models can still provide basic physiology and pathology relevant to human AMD.

We have reported that a loss-of-function variation within CX3CR1 (T280M/V249I) is associated with AMD in a case-control study. This association was further demonstrated via molecular pathological analyses. CX3CR1 polymorphisms are associated with an increased risk of AMD development [5]. Decreased CX3CR1 expression is detected in AMD eyes, in particular, within the macular region $[5,6]$. Interestingly, $C x 3 c r 1$-deficient mice have recently been reported to develop AMD-like features including 'drusen' formation, progressive accumulation of subretinal microglia and photoreceptor degeneration in aged animals $[7,8]$.

Senescent $C c l 2$ - or $C c r 2$-deficient mice are reported to develop AMD-like pathology including accumulation of lipofuscin in the retinal pigment epithelium (RPE) drusen, photoreceptor atrophy and choroidal neovascularization [9]. Complement and IgG deposits are also found in the RPE and choroid in these mice. Impaired macrophage function may contribute to AMD pathology in this model.

The hypothesis that deficiencies in both $C \times 3 \mathrm{crl}$ and Ccl 2 might have a synergistic effect resulting in a phenotype displaying typical AMD features with early onset and high penetrance has led us to generate a $\mathrm{Ccl} 2 / \mathrm{C} \times 3 \mathrm{crl}$ double-knockout (DKO) [10]. This article highlights the pathological features of our DKO mice.

\section{Generation of DKO Mice}

$\mathrm{C} \times 3 \mathrm{crl}^{-/-}$mice on the C57BL/6 background (kindly provided by Dr. Philip Murphy, NIAID/NIH) were crossbred with $\mathrm{Ccl} 2^{-/-}$C57BL/6 mice (kindly provided by Drs. Bao Lu and Barrett J. Rollins of Children's Hospital, Harvard Medical School) to generate $\mathrm{Ccl}^{+/-} / \mathrm{C} \times 3 \mathrm{crl}^{+/-}$mice. The heterozygous mice were then intercrossed to generate various combinations of the 4 alleles including the $\mathrm{Ccl}^{-/-} / \mathrm{C} \times 3 \mathrm{Crl}^{-/-}$mice. Among the $400 \mathrm{~F} 2$ pups analyzed, 12 were $\mathrm{Ccl}^{-/-} / \mathrm{C} \times 3 \mathrm{crl}^{-/-}$, indicating an abnormal Mendelian segregation (1 in 16 expected) [10]. Funduscopy was performed on these $\mathrm{Ccl} 2^{-/-} / \mathrm{C} \times 3 \mathrm{Crl}^{-/}$mice. The 2 $\mathrm{Ccl} 2^{-/-} / \mathrm{C} \times 3 \mathrm{crl}^{-/-}$mice with the most retinal drusen-like lesions were selected as the breeding pair to generate the DKO strain.

\section{Characterization of DKO Mice}

DKO mice appear normal although slightly underweight and smaller in size. They are less fertile, averaging 4 pups per litter as compared to 8 pups in normal C57BL/6 mice. Loss of hair and pigmentation are observed in some DKO. Most importantly, all DKO mice show multiple small retinal lesions [10]. These lesions are similar to human drusen and can be observed as early as at 6 weeks of age. The round or dome-shaped, yellowish deposits are observed mostly within the deep retina subretinal space (fig. 1). Most lesions will become larger and confluent (by 4-6 months) and some progress to flattened or scar-like atrophic areas with aging ( $>6$ months).

The most prominent histopathology noted is the presence of abnormal RPE cells (fig. 2). Focal or diffuse RPE hypopigmentation, depigmentation, vacuolization and atrophy resulting from loss of melanosomes and increased lipofuscin are frequently observed [10]. In some rare cases, focal RPE hyperpigmentation is also observed. An abnormal thickened Bruch membrane further characterized by irregular deposits also develops. In general, these drusen appear to be much smaller as compared to classical drusen in AMD patients. Spontaneous choroidal neovascularization develops in approximately $15 \%$ of DKO mice. These choroidal neovascularizations are surrounded by little or no areas of hemorrhage and are often tiny and fragile, thus they are difficult to identify. Photoreceptor abnormalities are usually in small foci of the outer nuclear layer. Photoreceptor atrophy is found in older DKO mice.

DKO mice demonstrate aberrant immunological responses. Complement factor deposits and microglial accumulation are detected surrounding, as well as within, the lesions [10]. These mice show decreased response to lipopolysaccharide as compared to C57BL/6 mice. This may be primarily due to the low expression of toll-like receptor 4 observed in the DKO mice [11]. DKO mice exhibit microglial activation impaired macrophage recruitment and function, which may be associated with the development of the observed AMD-like lesions.

A2E (N-retinylidene-N-retinylethanolamine), a major fluorophore of lipofuscin, is a derivative of retinoid metabolism. Lipofuscin is a product of RPE phagocytosis of photoreceptor outer segments and has been shown to increase and accumulate in the RPE of AMD eyes. A 3- to 4 -fold increase in $\mathrm{A} 2 \mathrm{E}$ is found within the retina and $\mathrm{RPE}$ of DKO as compared to C57BL/6 mice [10]. Using spectral fluorescence microscopy, a higher autofluorescence, originating mainly from $\mathrm{A} 2 \mathrm{E}$, is measured in both young and old DKO as compared to C57BL/6 mice (fig. 3a, b).

Ophthalmic Res 2008;40:124-128 


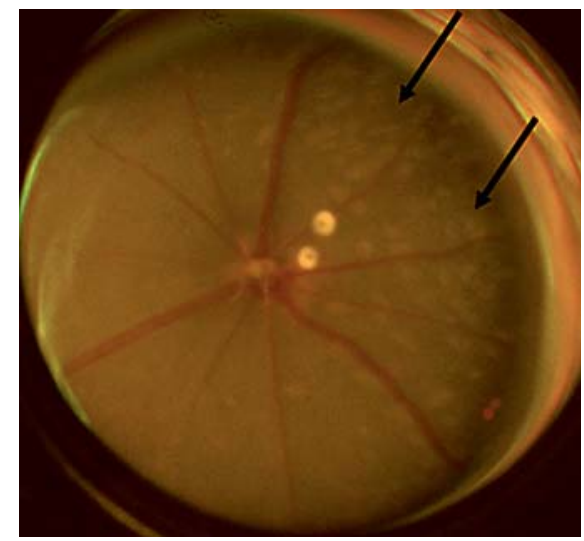

Fig. 1. Funduscopy showing multiple drusen-like lesions (arrows) in a DKO mouse eye.

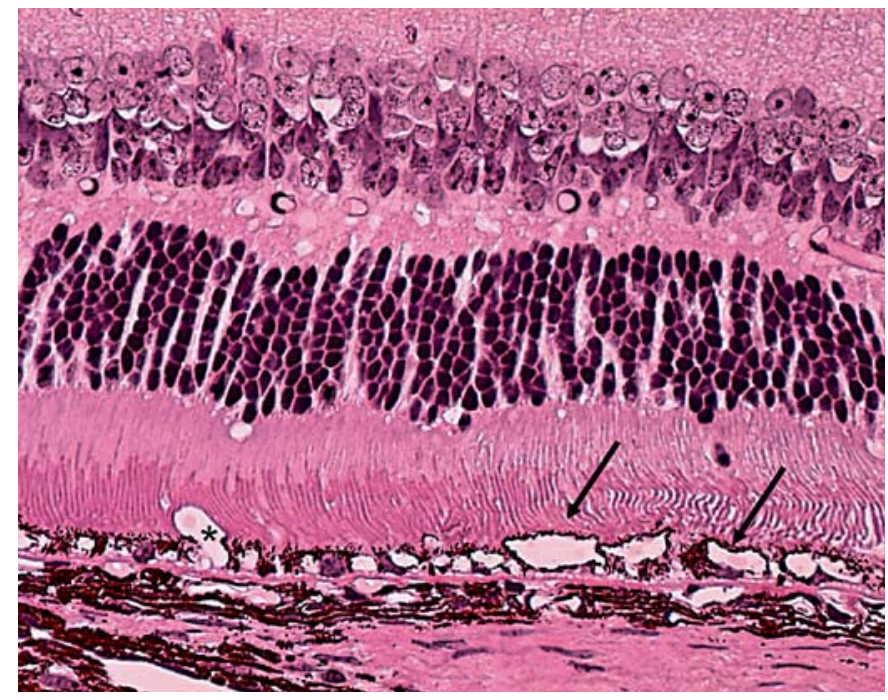

Fig. 2. Photomicrograph showing severe RPE degeneration and irregular Bruch's membrane (arrows = RPE vacuolation; asterisk = ill-defined neovascular lumen). Hematoxylin and eosin. Original magnification $\times 400$.

The autofluorescence is associated specifically with the RPE and has a spectral emission peak at $\sim 600-615 \mathrm{~nm}$. The emission spectrum is consistent with that of unbleached RPE cell cultures fed A2E when excited at 458 $\mathrm{nm}$. This likely reflects that more A2E and perhaps its precursors are present in the RPE of the DKO and the spectrum is not dominated by oxidized A2E granules, which have an emission maximum typically between 530 and $560 \mathrm{~nm}$ when excited at $458 \mathrm{~nm}$ [Majumdar and Bonner, unpublished data].

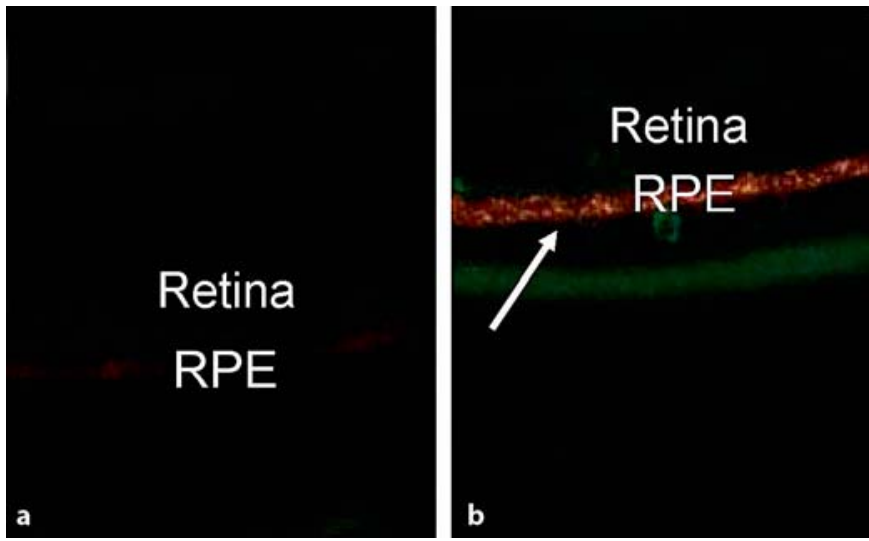

Fig. 3. Spectral fluorescent microscopic examinations showing very faint A2E staining (orange-yellow color) in the RPE of a wildtype (a) but strong A2E deposits (arrow) in a DKO mouse (b). Original magnification $\times 100$.
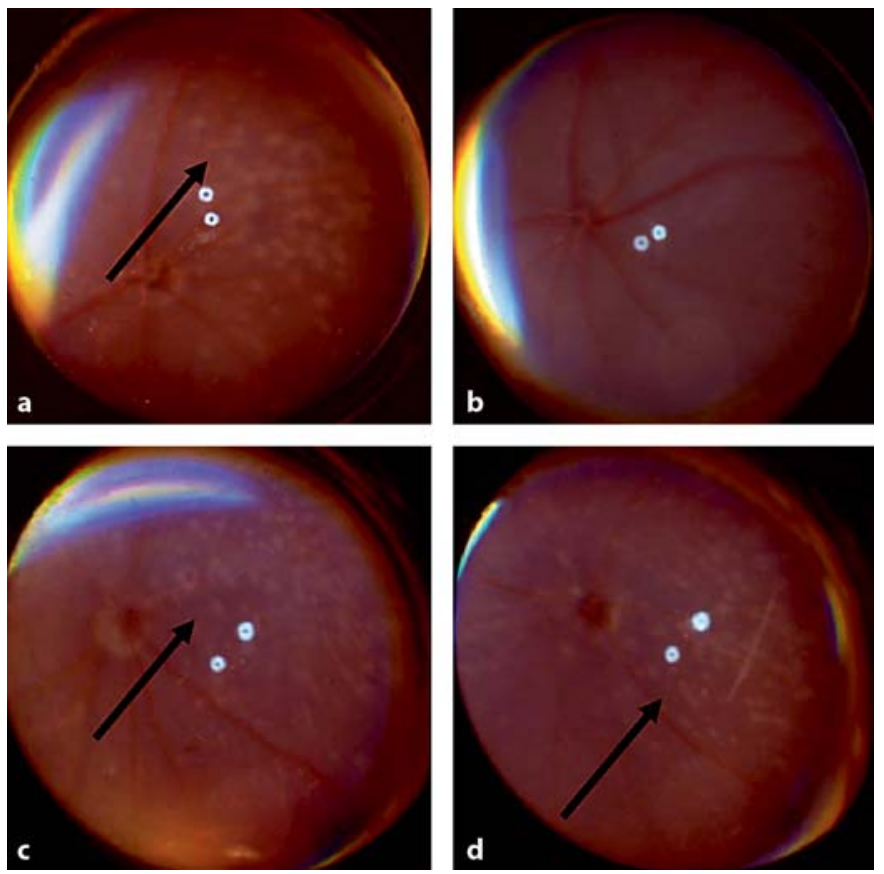

Fig. 4. Funduscopic images of 2 DKO mice showing decrease of retinal lesions (arrow) in the mouse fed with high omega-3 LCPUFA (a, b) but increase of retinal lesions (arrows) in the mouse fed with diet deprived of omega-3 LCPUFA (c, d) after 1 month.

Proteomics of the retina and RPE demonstrate 4 differentially expressed proteins in DKO [10]. One of them is the ERp29 precursor. ERp29 protein is associated with neurodegenerative diseases [12]. ERp29 is a resident endoplasmic reticulum (ER) protein, which functions as a

Chan/Ross/Shen/Ding/Majumdar/ Bojanowski/Zhou/Salem/Bonner/Tuo 


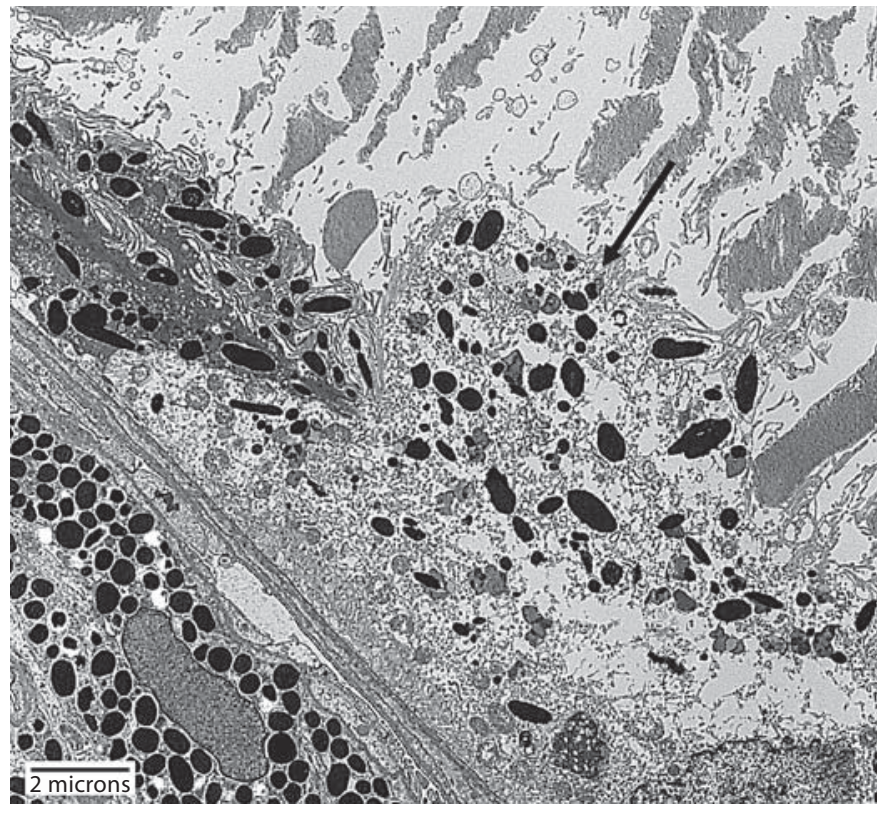

Fig. 5. Transmission electron micrograph of a DKO mouse shows severe degeneration of RPE cell (arrow) and disorganized and partial loss of photoreceptor outer segments.

chaperone $[13,14]$. Chaperones are proteins that help and guide other proteins as they fold and progress along the productive pathways. Misfolded proteins could aggregate and interfere with intracellular movement. Many chaperones are upregulated under conditions where misfolded proteins accumulate. ERp29 also facilitates the export of membrane or secretory proteins. ERp29 protein is considered to be associated with neurodegenerative diseases [12]. Significantly lower levels of ERp29 (protein and transcript) are found in the eyes, particularly within the retinal lesions, of DKO mice as compared to C57BL/6 mice [10]. This finding supports the reports of decreased ERp29 in the aging retina and AMD maculae $[15,16]$. Low ERp29 protein levels may impact chaperone function and lead to the accumulation of incompletely folded aggregates such as lipofuscin or drusen, eventually resulting in the RPE damage observed in DKO mice.

\section{Implications of DKO Mice}

Omega-3 fatty acids are long-chain polyunsaturated fatty acids (LCPUFA) that cannot be synthesized de novo by mammals [17]. They have neuroprotective, anti-inflammatory and antiangiogenic effects [18-20]. One of the major components of omega-3 LCPUFA is docosa- hexaenoic acid, which activates HSP70, a chaperone protein. Omega-3 LCPUFA is metabolized in the ER and stimulates post-ER presecretory proteolysis [21]. Higher intake of omega-3 LCPUFA and fish is associated with a decreased likelihood of developing AMD $[22,23]$.

In a preliminary experiment, DKO mice were fed with either a high or low in omega-3 LCPUFA starting from preconception. Although similar retinal lesions were observed at 6 weeks of age in both groups, the number of lesions was decreased in the mice that ingested a high omega-3 LCPUFA diet (fig. 4a, b). In contrast, in the mice that ingested a diet deprived of omega-3 LCPUFA, the retinal lesions continued to progress (fig. $4 \mathrm{c}, \mathrm{d}$ ). The likely cause for this observation is the enriched docosahexaenoic acid intake in the mice fed with the high omega-3 LCPUFA diet. Docosahexaenoic acid is shown to promote RPE cell survival by being the precursor of neuroprotectin D1. Neuroprotectin D1 inhibits oxidativestress-mediated proinflammatory gene induction and apoptosis [24]. Further investigations on these mice are currently underway in our laboratory.

\section{Conclusion}

DKO mice present a board spectrum of clinical, biochemical, immunological and pathological features of human AMD lesions. The spontaneously developing features are highly reproducible. In these mice, the disease onset is earlier than that observed in most genetically engineered AMD mouse models. DKO mice implicate the important roles of certain inflammatory molecules and chaperone proteins in AMD pathogenesis. DKO mice may be used to direct future therapeutic strategies, such as the attenuation of retinal pathology with a diet rich in omega-3 LCPUFA for the treatment of AMD.

References

1 Resnikoff S, Pascolini D, Etya’ale D, Kocur I, Pararajasegaram R, Pokharel GP, Mariotti SP: Global data on visual impairment in the year 2002. Bull World Health Organ 2004; 82:844-851.

- 2 Smith W, Assink J, Klein R, Mitchell P, Klaver CC, Klein BE, Hofman A, Jensen S, Wang JJ, de Jong PT: Risk factors for age-related macular degeneration: Pooled findings from three continents. Ophthalmology 2001; 108:697-704

3 Gehrs KM, Anderson DH, Johnson LV, Hageman GS: Age-related macular degeneration - emerging pathogenetic and therapeutic concepts. Ann Med 2006;38:450-471. 
4 Rakoczy PE, Yu MJ, Nusinowitz S, Chang B, Heckenlively JR: Mouse models of age-related macular degeneration. Exp Eye Res 2006; 82:741-752.

$\checkmark 5$ Tuo J, Smith BC, Bojanowski CM, Meleth AD, Gery I, Csaky KG, Chew EY, Chan CC: The involvement of sequence variation and expression of CX3CR1 in the pathogenesis of age-related macular degeneration. FASEB J 2004;18:1297-1299.

6 Chan CC, Tuo J, Bojanowski CM, Csaky KG, Green WR: Detection of CX3CR1 single nucleotide polymorphism and expression on archived eyes with age-related macular degeneration. Histol Histopathol 2005;20:857863.

7 Combadiere C, Feumi C, Raoul W, Keller N, Rodero M, Pezard A, Lavalette S, Houssier M, Jonet L, Picard E, Sirinyan M, Deterre P, Ferroukhi T, Cohen SY, Chauvaud D, Jeanny J, Chemtob S, Behar-Cohen F, Sennlaub F: CX3CR1 dependent subretinal microglia cell accumulation is associated with cardinal features of age-related macular degeneration. J Clin Invest 2007;117:2920-2928.

8 Raoul W, Combadiere C, Keller N, Rodero M, Jeanny JC, Behar-Cohen F, Sennlaub F: Retinal degeneration occurs in CX3CR1 knockout animals secondary to subretinal microglia accumulation. Invest Ophthalmol Vis Sci 2007;48:3023.

-9 Ambati J, Anand A, Fernandez S, Sakurai E, Lynn BC, Kuziel WA, Rollins BJ, Ambati BK: An animal model of age-related macular degeneration in senescent Ccl-2- or Ccr-2-deficient mice. Nat Med 2003;9:1390-1397.
10 Tuo J, Bojanowski CM, Zhou M, Shen D, Ross RJ, Rosenberg KI, Cameron DJ, Yin C, Kowalak JA, Zhuang Z, Zhang K, Chan CC: Murine $\mathrm{ccl} 2 / \mathrm{cx} 3 \mathrm{crl}$ deficiency results in retinal lesions mimicking human age-related macular degeneration. Invest Ophthalmol Vis Sci 2007;48:3827-3836.

11 Shen D, Tuo J, Bojanowski CM, Zhou M, Ross RJ, Chan CC: Hyporeactive ocular responses to lipopolysaccharide in $\mathrm{ccl} 2 / \mathrm{cx} 3 \mathrm{cr} 1$ double deficient mice. Invest Ophthalmol Vis Sci 2006;47:4521.

12 Willis D, Li KW, Zheng JQ, Chang JH, Smit A, Kelly T, Merianda TT, Sylvester J, van Minnen J, Twiss JL: Differential transport and local translation of cytoskeletal, injuryresponse, and neurodegeneration protein mRNAs in axons. J Neurosci 2005;25:778791.

13 Mkrtchian S, Fang C, Hellman U, IngelmanSundberg M: A stress-inducible rat liver endoplasmic reticulum protein, erp29. Eur J Biochem 1998;251:304-313.

14 Sargsyan E, Baryshev M, Szekely L, Sharipo A, Mkrtchian S: Identification of erp29, an endoplasmic reticulum lumenal protein, as a new member of the thyroglobulin folding complex. J Biol Chem 2002;277:1700917015 .

15 Li D, Sun F, Wang K: Protein profile of aging and its retardation by caloric restriction in neural retina. Biochem Biophys Res Commun 2004;318:253-258.

16 Ethen CM, Reilly C, Feng X, Olsen TW, Ferrington DA: The proteome of central and peripheral retina with progression of agerelated macular degeneration. Invest Ophthalmol Vis Sci 2006;47:2280-2290.
17 Salem NJ: Omega-3 fatty acids: molecular and biochemical aspects; in Spiller G, Scala J (eds): New Protective Roles of Selected Nutrients in Human Nutrition. New York, Liss, 1989, pp 109-228.

18 Sterescu AE, Rousseau-Harsany E, Farrell C Powell J, David M, Dubois J: The potential efficacy of omega-3 fatty acids as anti-angiogenic agents in benign vascular tumors of infancy. Med Hypotheses 2006;66:1121-1124.

19 Goldberg RJ, Katz J: A meta-analysis of the analgesic effects of omega-3 polyunsaturated fatty acid supplementation for inflammatory joint pain. Pain 2007;129:210-223.

20 Bazan NG: Neuroprotectin D1 (NPD1): a DHA-derived mediator that protects brain and retina against cell injury-induced oxidative stress. Brain Pathol 2005;15:159-166.

-21 Narayanan NK, Narayanan BA, Bosland M, Condon MS, Nargi D: Docosahexaenoic acid in combination with celecoxib modulates hsp70 and p53 proteins in prostate cancer cells. Int J Cancer 2006;119:1586-1598.

22 Sangiovanni JP, Chew EY: The role of omega3 long-chain polyunsaturated fatty acids in health and disease of the retina. Prog Retin Eye Res 2005;24:87-138.

23 Sangiovanni JP, Chew EY, Clemons TE, Davis $\mathrm{MD}$, Ferris FL 3rd, Gensler GR, Kurinij N, Lindblad AS, Milton RC, Seddon JM, Sperduto RD: The relationship of dietary lipid intake and age-related macular degeneration in a case-control study: AREDS Report No 20. Arch Ophthalmol 2007;125:671-679.

24 Bazan NG: Cell survival matters: docosahexaenoic acid signaling, neuroprotection and photoreceptors. Trends Neurosci 2006; 29:263-271. 